\title{
Actively Open-Minded Thinking, Bullshit Receptivity, and Susceptibility to Framing: Evaluating the Dual-Process Account in North America and Bulgaria
}

Nikolay R. Rachev ${ }^{1}$, Sandra J. Geiger ${ }^{2}$, Jáchym Vintr $^{3}$, Desislava Kirilova ${ }^{1}$, Anna Nabutovsky ${ }^{4,5}$, and Joakim Nelsson ${ }^{6}$

${ }^{1}$ Department of General, Experimental, Developmental, and Health Psychology, Faculty of Philosophy, Sofia University St. Kliment Ohridski, Sofia, Bulgaria

${ }^{2}$ Department of Psychology, Faculty of Social and Behavioural Sciences, University of Amsterdam, Amsterdam, The Netherlands

${ }^{3}$ Department of Psychology, Faculty of Arts, Charles University, Prague, Czechia

${ }^{4}$ Department of Psychology, Department of Statistical Science, University of Toronto, Toronto, Ontario, Canada

${ }^{5}$ School of Law, University of California, Los Angeles, Los Angeles, California, USA

${ }^{6}$ Department of Psychology, Faculty of Social Sciences, Uppsala University, Uppsala, Sweden

This version of the article may not completely replicate the final authoritative version to be published in the European Journal of Psychological Assessment at https://doi.org/10.1027/10155759/a000685. It is not the version of record and is therefore not suitable for citation. Please do not copy or cite without the permission of the authors. 


\section{Author Note}

Nikolay R. Rachev iDhttps://orcid.org/0000-0002-5654-2883

Sandra J. Geiger (Dhttps://orcid.org/0000-0002-3262-5609

Jáchym Vintr Đhttps://orcid.org/0000-0002-7228-3287

Anna Nabutovsky iDhttps://orcid.org/0000-0003-4155-0263

Joakim Nelsson (Dhttps://orcid.org/0000-0002-8305-6338

Correspondence concerning this article might be addressed to Nikolay R. Rachev, Department of General, Experimental, Developmental, and Health Psychology, 15 Tsar Osvoboditel Blvd., 1504, Sofia University St. Kliment Ohridski, Sofia, Bulgaria. E-mail: nrrachev@ phls.unisofia.bg 


\begin{abstract}
The framing effect occurs when different presentations of the same problem lead to predictably different preferences. The dual-process framework of higher cognition assumes that the effect violates rational principles, but alternative accounts and recent evidence have contested this interpretation. Contributing to this debate, we tested the dual-process assumption by investigating associations between susceptibility to framing and the willingness and ability to think in line with rational norms, conceptualized as actively open-minded thinking and pseudoprofound bullshit receptivity. We conducted two online studies among North American $(N=$ 259) and Bulgarian $(N=248)$ university students and administered several framing problems within subjects, presumably a necessary condition for the associations to appear. Confirmatory factor analyses showed that susceptibility to framing was associated with decreased actively open-minded thinking and increased bullshit receptivity in both sites. Exploratory multi-group analyses demonstrated partial strong invariance and showed that the findings generalize across both sites in terms of direction and partially in terms of magnitude. These results broadly support the dual-process account of the framing effect. Our study further contributes to adapting existing measures to a novel setting and expanding the findings across borders and populations.
\end{abstract}

Keywords: framing effect, actively open-minded thinking, bullshit receptivity, dualprocess account, confirmatory factor analysis 
ACTIVELY OPEN-MINDED THINKING, BULLSHIT RECEPTIVITY, AND FRAMING 4

\section{Actively Open-Minded Thinking, Bullshit Receptivity, and Susceptibility to Framing:}

\section{Evaluating the Dual-Process Account in North America and Bulgaria}

Imagine you are asked to evaluate a vaccine described as having an $80 \%$ success rate and, sometime later, a vaccine described as having a $20 \%$ failure rate. If you are like many people, chances are you like the former description more than the latter, thus showing a framing effect, whereby different presentations of the same options lead to predictably different responses (Levin et al., 1998). Does the discrepancy between your two evaluations result from shallow thinking that could be overcome, had you given it more thought? According to the dual-process framework of higher cognition (Evans \& Stanovich, 2013; Kahneman, 2003), the answer is yes but alternative accounts and recent evidence question this assumption (e.g., Mandel, 2014; Sher \& McKenzie, 2006). Contributing to this debate, the present study aimed to test the dual-process assumption by investigating whether actively open-minded thinkers and those who are more successful in detecting pseudo-profound bullshit are less susceptible to framing manipulations. Crucially, we tested these propositions in two sites, North America and Bulgaria, which not only served to adapt existing measures to a novel setting but also to test whether our findings generalize across borders and populations.

\section{The Framing Effect: A Thinking Bias?}

The dual-process framework of higher cognition (Evans \& Stanovich, 2013; Kahneman, 2003) distinguishes between two types of processes. Intuitive Type 1 processes (System 1) require minimal resources of the limited working memory capacity and are typically fast and effortless, while deliberate Type 2 processes (System 2) rely on working memory and tend to be slower and effortful. Often, a conflict arises between heuristic Type 1 outputs and some normative consideration. Failure to detect this conflict or inefficient double-checking with Type 
2 processes lead to systematic deviations from norms of rational thought, so-called biases (De Neys, 2018; Pennycook, Fugelsang, et al., 2015a). One particular bias, the framing effect, violates the rational principle of descriptive invariance stating that preferences should not be affected by the way options are presented (Tversky \& Kahneman, 1986). Presumably, the effect results from System 2 passively accepting the intuitive decision delivered by System 1 which is heavily influenced by salient but irrelevant contextual features, namely the presented frame (Kahneman, 2003). Hence, individuals who are willing to revise their first hunches would be less susceptible to framing, much like they are less susceptible to other thinking biases (Pennycook, Fugelsang, et al., 2015b).

Alternative accounts, however, question the dual-process account and its assumption that the framing effect violates norms of rational thought. For instance, the two versions of a framing problem might not necessarily be interpreted as equivalent (Kühberger \& Tanner, 2010; Mandel, 2014; Sher \& McKenzie, 2006). Regarding our opening problem, one version might be interpreted as "at least $80 \%$ success rate", while the other one as "at least $20 \%$ failure rate." Careful thinkers would realize that the former is superior, and further thinking is unlikely to lead to equal ratings.

\section{Susceptibility to Framing and Thinking Dispositions: A Way to Contribute to the Debate}

It is thus possible to test the dual-process account of framing by investigating whether susceptibility to framing is related to one's willingness and ability to think in accordance with rational norms. Using this approach, Mandel and Kapler (2018) failed to find a reliable association between susceptibility to framing and various measures of analytic cognitive style, or the propensity to rely on Type 2 rather than Type 1 processes. Pointing to similarly weak relations in previous studies (e.g., West et al., 2008), they concluded that "any theory positing 
that framing effects are largely due to reliance on heuristic 'System 1' reasoning processes is wrong" (p. 10).

However, Mandel and Kapler (2018) used a single framing task administered between subjects, which might be suboptimal for testing the predictions of the dual-process account. A single encounter with a framing task lacks a cue to a potential conflict and thus provides no advantage for more analytical thinkers (Kahneman, 2003). In contrast, within-subjects administrations allow decision makers to encounter both versions of the task and establish their logical equivalence. In this context, the dual-process account predicts that more analytic thinkers will be more likely to follow the invariance principle and thus be less susceptible to framing manipulations than less analytic individuals. The specific superiority of analytic thinkers in resisting framing in within- but not in between-subjects contexts has received some empirical support (LeBoeuf \& Shafir, 2003). Accordingly, we chose a within-subjects setting where participants were presented with both versions of several framing problems (Bruine de Bruin et al., 2007).

\section{Actively Open-Minded Thinking (AOT) as a Measure of Rational Thought}

A salient feature of rational thinkers is that they are actively open-minded (Baron, 2008, 2019b). That is, before deciding on a problem, they actively search for reasons why their favored conclusions might be wrong and are willing to update their beliefs - and their confidence therein — in the face of new evidence. Baron (1991) has argued that individuals' own standards of good thinking are predictive of how individuals actually think. Hence, individuals whose beliefs about thinking match better the prescriptive AOT standards would be less prone to thinking biases. Indeed, AOT is associated with utilitarian moral judgment, normative problemsolving (Baron et al., 2015), and reduced overconfidence (Haran et al., 2013). Based on the dual- 
process view, AOT would be negatively related to susceptibility to framing for both North Americans (Hypothesis 1a) and Bulgarians (Hypothesis 1b).

\section{Pseudo-Profound Bullshit Receptivity (BSR) and Failure to Detect Conflicts}

Susceptibility to framing might also be associated with the tendency to uncritically accept meaningless statements as profound. Known as pseudo-profound bullshit receptivity (BSR), this tendency has been related to a host of cognitive biases (Pennycook, Cheyne, et al., 2015). BSR consists of two factors (Pennycook, Cheyne, et al., 2015): a general proneness to uncritically accept claims of variable credibility and a specific failure to detect bullshit. If susceptibility to framing is a thinking bias, as suggested by the dual-process framework, it might be related to both factors. A generally unskeptical attitude toward novel information is likely to favor passive acceptance of the presented frame (Kahneman, 2003). Furthermore, both failure to detect bullshit and framing susceptibility (in within-subjects contexts) might represent instances of a more general failure to detect conflict. Hence, the dual-process account would predict that BSR is positively associated with susceptibility to framing for both North Americans (Hypothesis 2a) and Bulgarians (Hypothesis 2b).

To test the proposed hypotheses and correct for measurement unreliability (Westfall \& Yarkoni, 2016), we used confirmatory factor analyses (CFA). As displayed in Figure 1, we expected a three-factor model with AOT, BSR, and susceptibility to framing as latent variables, because every scale measures a theoretically separate construct. We predicted correlations between all latent variables, as proposed in the hypotheses and shown in previous research (Turpin et al., 2019). Overall, we expected that the proposed model would fit the data from (a) North America and (b) Bulgaria at least adequately (Hypothesis 3). 


\section{Method}

We conducted a dual-site online survey assessing AOT, BSR, and susceptibility to framing. The survey was administered among North American and Bulgarian participants, following the same protocol.

\section{Participants}

\section{Sampling Plan}

A priori power analyses were used to determine the sample size required to detect (a) the target effect sizes (Wang \& Rhemtulla, 2020) and (b) model misspecifications based on the test of close and not-close fit of the Root Mean Square Error of Approximation (RMSEA; MacCallum et al., 1996). Following previous comparable research, we expected moderate disattenuated correlations for BSR $\left(r_{\text {disattenuated }}=.28\right.$ and $r_{\text {observed }}=.20$; Pennycook, Cheyne, et al., 2015, Rachev et al., 2021) and AOT ( $r_{\text {disattenuated }}=-.29$ and $r_{\text {observed }}=-.18$; Toplak et al., 2011) with susceptibility to framing. The power analysis with the pwrSEM app (Wang \& Rhemtulla, 2020) was based on the CFA model in Figure 1 and yielded 240 participants per site to detect the expected effects with 93\% (AOT-Framing) and $88 \%$ (BSR-Framing) power. The power analysis with the semTools R package (Version 0.5-2; Jorgensen et al., 2019) suggested at most 229 participants per site to detect model misspecifications, with $90 \%$ power and a cut-off value of RMSEA $\leq .08$ for acceptable fit. Details to replicate both power analyses can be found in Supplement 1 (https://osf.io/hx8qt/).

\section{Figure 1}

CFA Model Including Expected Parameter Estimates for the Power Analysis 


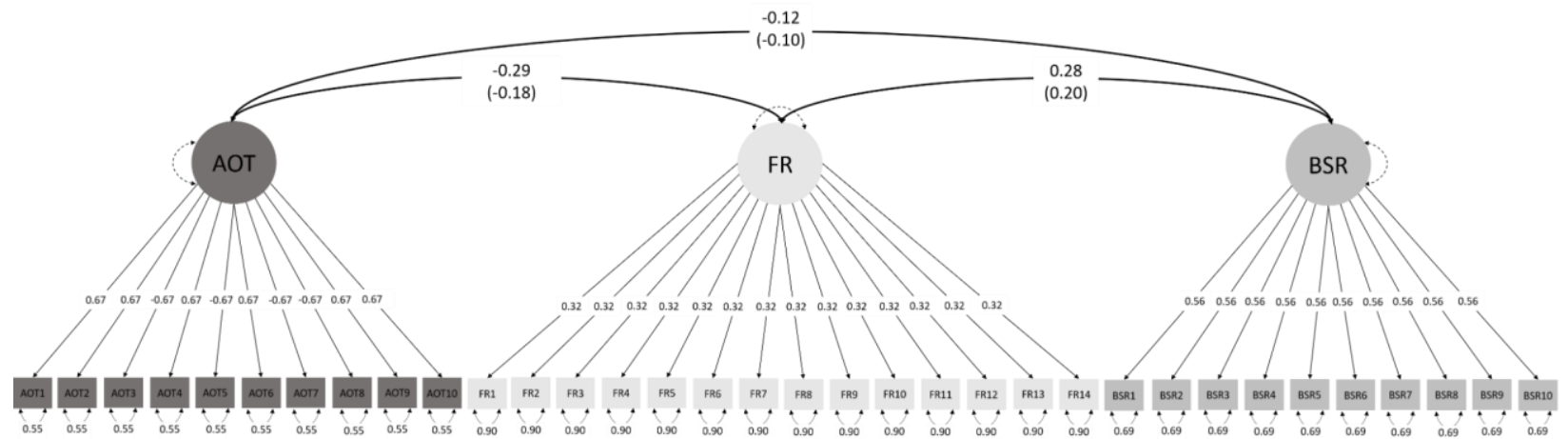

Note $. \mathrm{FR}=$ susceptibility to framing, AOT $=$ actively open-minded thinking, and BSR $=$ bullshit receptivity. The CFA model has 524 degrees of freedom with variances of the latent variables fixed to 1. The average factor loadings have been estimated using the Spearman-Brown prediction formula based on Cronbach's $\alpha_{\mathrm{FR}}=.62$ (Bruine de Bruin et al., 2007), Cronbach's $\alpha_{\mathrm{AOT}}=.89$ (Baron \& High II, 2019), and Cronbach's $\alpha_{\mathrm{BSR}}=.82$ (Pennycook, Cheyne, et al., 2015). The residual variances have been set to $1-\lambda^{2}$. The correlations represent disattenuated estimates; the values in parentheses are the uncorrected estimates obtained in previous studies with identical or similar constructs (Pennycook, Cheyne, et al., 2015; Rachev et al., 2021; Toplak et al., 2011; Turpin et al., 2019).

Following the power analyses and accounting for potential outlier exclusions, we aimed to collect 250 complete responses per site after excluding responses classified as duplicate, inattentive, or too fast. As there were more outliers than expected, we deviated from this plan and collected 250 complete responses per site after applying the three pre-registered criteria and excluding outliers.

For inclusion, participants needed to be at least 18 years old and university students with a major other than psychology to minimize familiarity with the framing effect. They were further required to be either (1) citizens and residents of North America (i.e., Canada or the U.S.) and 
native English speakers, or (2) citizens and residents of Bulgaria and native Bulgarian speakers. Participants in both sites were recruited via social media and emails and compensated via a random draw of $90(85 \times \$ 5$ and $5 \times \$ 30)$ gift cards for North American participants and 165 $(160 \times \$ 3$ and $5 \times \$ 20)$ gift cards for Bulgarian participants. The final samples are presented in Table 1.

\section{Data Exclusion}

Participants were excluded if they failed to answer all items, revoked their consent, or completed the survey multiple times, as indicated by identical IP addresses, withdrawal codes, and demographic information (i.e., age, gender, major, and year of studies; Koo \& Skinner, 2005). Participants were also excluded if they failed the attention check. A substantial number of participants ( $n=51$ of 341 in North America and $n=7$ of 282 in Bulgaria) completed the survey faster than ten minutes. As these responses were no outliers according to our pre-registered criterion (i.e., 3.5 median absolute deviations from the overall time), we deviated from our plan and included only responses with a minimum completion time of $10 \mathrm{~min}$.

Multivariate outliers were detected using generalized Cook's distance from the $\mathrm{R}$ package influence.SEM (Version 2.2; Pastore \& Altoe', 2018), using the default boxplot criterion Q3+(Q3-Q1)×1.5 (with Q1: first quartile and Q3: third quartile; Koran \& Jaffari, 2020). As a result, 31 influential multivariate outliers from the North American sample and 23 from the Bulgarian sample were excluded listwise. For robustness checks, the analyses were additionally performed including outliers and reported in Supplement 2 (https://osf.io/hx8qt/). Overall, the results were relatively robust toward outlier exclusions.

\section{Table 1}

Description of the Final Samples 


\begin{tabular}{|c|c|c|c|}
\hline & & North America & Bulgaria \\
\hline & $N$ & 259 & 248 \\
\hline \multirow[t]{3}{*}{ Gender } & Males & 131 & 53 \\
\hline & Females & 113 & 192 \\
\hline & Other & 15 & 3 \\
\hline Age (in years) & $M(S D)[\operatorname{Min}, \operatorname{Max}]$ & $21.9(4.2)[18,49]$ & $23.2(6.2)[18,52]$ \\
\hline \multirow[t]{8}{*}{ Education } & No high school & 1 & 0 \\
\hline & High school & 184 & 202 \\
\hline & Bachelor's degree & 68 & 34 \\
\hline & Master's degree & - & 12 \\
\hline & Doctorate & 1 & 0 \\
\hline & Most common degrees & Computer science (40) & Philology (49) \\
\hline & & Engineering (35) & Computer science (28) \\
\hline & & Biology (22) & Economics (27) \\
\hline
\end{tabular}

\section{Materials}

The survey assessed participants' AOT, BSR, and susceptibility to framing. The Bulgarian version was created from the original English-language materials using forward and backward translation with four independent, experienced translators.

The Actively Open-Minded Thinking Scale assessed self-reported willingness to thoroughly consider evidence and update one's opinion accordingly, on a five-point scale from 1 (strongly disagree) to 5 (strongly agree). After the fifth item, the following attention check was included with the same response scale: "Please select the option 'neutral' and proceed to the following question." 
The Bullshit Receptivity Scale (Pennycook, Cheyne, et al., 2015; Bulgarian translation by Rachev et al., 2021) consisted of ten statements with a seemingly deep meaning and correct syntactic structure, created by two generators randomly mashing together words pertaining to New Age vocabulary. To obscure their purpose, they were intermixed with ten prototypically profound, motivational statements, which were solely used for exploratory purposes. Participants rated the profoundness of both types of statements on a five-point scale from 1 (not at all profound) to 5 (very profound).

The Resistance to Framing Scale is a 14-item subscale from the Adult Decision-Making Competence Index (Bruine de Bruin et al., 2007). It assessed susceptibility to risky-choice and attribute framing (seven problems each) on a six-point scale, with two formally equivalent versions per problem, one framed positively and one framed negatively. Susceptibility to framing was represented by the absolute deviation between the ratings in the positive and the corresponding negative frame for every problem (Bruine de Bruin et al., 2007), with higher scores indicating stronger susceptibility.

\section{Procedure}

Participants completed the online survey administered in their native language via Qualtrics. The study had been approved by the Research Ethics Committees at both sites. After providing informed consent and demographics, participants were presented with the positive and negative frame block, in a counterbalanced order, whereby the risky-choice subblock was always presented first within each frame block (Bruine de Bruin et al., 2007). Between the two frame blocks, participants completed the AOT and BSR, in randomized order, separating the administration of the positive and the negative frame by approximately 5 min (Aczel et al., 2018). Items of every scale and framing problems within a subblock were randomized (excluding 
the attention check) and forced-response. After being debriefed, participants were redirected to a separate survey recording their email address for compensatory purposes.

\section{Statistical Analyses}

All analyses were performed using R (Version 4.0.2) and a threshold of $\alpha=.05$ for statistical significance. To test the proposed hypotheses, we fit a three-factor CFA model for each site (Figure 1) in lavaan (Version 0.6-6; Rosseel, 2012). We used Maximum-Likelihood (ML) estimation with robust standard errors and Satorra-Bentler scaled test statistics for all models, as the Henze-Zirkler test (R package $M V N$, Version 5.8, Korkmaz et al., 2014) showed that multivariate normality was always violated. Based on these models, we assessed each scale's reliability using McDonald's $\omega_{1}$ in semTools (Version 0.5-3; Jorgensen et al., 2019), with $\omega_{1} \geq .60$ representing acceptable reliability. Model fit was evaluated based on the $\chi^{2}$-test of exact fit combined with several fit indices, as shown in Table 2. If the model did not fit (i.e., most indicators did not show at least acceptable fit), residual covariances were added based on the highest modification indices. The modified model tested the hypotheses if the indices suggested acceptable fit, and if the modified model fit better than the original model (i.e., two of three criteria, including significant likelihood-ratio test, lower AIC and BIC).

We further fit a multi-group CFA model to exploratively test differences of the hypothesized associations between the two sites (Fischer \& Karl, 2019). This included testing configural (i.e., equal models), weak factorial (i.e., equal factor loadings), strong factorial (i.e., equal intercepts), and strict (i.e., equal residual variances and covariances) measurement invariance.

The full details of the pre-registered contingency plan are available in our Stage 1 report at https://osf.io/hx8qt/. 


\section{Table 2}

Cut-Off Values for the Fit Indices

\begin{tabular}{|c|c|c|c|}
\hline & RMSEA & $\begin{array}{l}\text { Incremental Fit Indices } \\
\text { (CFI/TLI, NNFI, IFI) }\end{array}$ & $\begin{array}{c}\text { SRMR } \\
\text { (only with a } \\
\text { significant } \chi^{2} \text {-test) }\end{array}$ \\
\hline Excellent & $<.06$ & $>0.95$ & $<.06$ \\
\hline Good & $<.07$ & $>0.92$ & $<.07$ \\
\hline Acceptable & $<.08$ & $>0.89$ & $<.08$ \\
\hline Questionable & $<.09$ & $>0.86$ & $<.09$ \\
\hline Poor & $<.10$ & $>0.83$ & $<.10$ \\
\hline Unacceptable & $>.10$ & $<0.83$ & $>.10$ \\
\hline
\end{tabular}

Note. Adapted from Greiff and Allen (2018). CFI = Comparative Fit Index; IFI = Incremental Fit Index; SRMR = Standardized Root Mean Square Residual; RMSEA = Root Mean Square Error of Approximation; TLI/NNFI = Tucker-Lewis Index/Non-Normed Fit Index

\section{Results}

\section{Study 1: North America}

\section{Descriptive Statistics and Reliability}

Descriptive statistics for each item are reported in Table 3. Generally speaking, susceptibility to framing and BSR were low, while AOT was high. Based on the selected model (see Confirmatory Analyses), the reliability for the susceptibility to framing (McDonald's $\omega_{1}=$ $.55)$ and AOT (McDonald's $\left.\omega_{1}=.54\right)$ scale did not meet the pre-specified cut-off value of $\omega_{1} \geq$ .60 and was therefore judged as questionable. The BSR scale was highly reliable (McDonald's $\left.\omega_{1}=.88\right)$.

\section{Table 3}

Descriptive Statistics for Each Item 


\begin{tabular}{|c|c|c|c|c|c|c|c|}
\hline & & \multicolumn{3}{|c|}{ North America } & \multicolumn{3}{|c|}{ Bulgaria } \\
\hline Item & $\begin{array}{c}\text { Potential } \\
\text { Minimum } \\
- \\
\text { Maximum }\end{array}$ & Mean & $\begin{array}{l}\text { Standard } \\
\text { Deviation }\end{array}$ & $\begin{array}{c}\text { Minimum } \\
- \\
\text { Maximum }\end{array}$ & Mean & $\begin{array}{l}\text { Standard } \\
\text { Deviation }\end{array}$ & $\begin{array}{c}\text { Minimum } \\
\text { - } \\
\text { Maximum }\end{array}$ \\
\hline RC_pesticide & $0-5$ & 1.09 & 1.25 & $0-5$ & 1.41 & 1.45 & $0-5$ \\
\hline RC_taxes & $0-5$ & 0.90 & 1.07 & $0-5$ & 0.86 & 1.15 & $0-5$ \\
\hline RC_dropout & $0-5$ & 0.88 & 1.18 & $0-5$ & 1.00 & 1.23 & $0-5$ \\
\hline RC_disease & $0-5$ & 1.14 & 1.33 & $0-5$ & 0.99 & 1.13 & $0-5$ \\
\hline RC_cancer & $0-5$ & 0.89 & 1.32 & $0-5$ & 0.96 & 1.30 & $0-5$ \\
\hline RC_stocks & $0-5$ & 0.98 & 1.18 & $0-5$ & 0.98 & 1.21 & $0-5$ \\
\hline RC_soldiers & $0-5$ & 1.13 & 1.21 & $0-5$ & 1.01 & 1.19 & $0-5$ \\
\hline AF_condom & $0-5$ & 0.40 & 0.65 & $0-3$ & 0.45 & 0.80 & $0-4$ \\
\hline AF_beef & $0-5$ & 0.54 & 0.85 & $0-4$ & 0.67 & 0.88 & $0-4$ \\
\hline AF_cheating & $0-5$ & 0.46 & 0.70 & $0-3$ & 0.62 & 1.03 & $0-5$ \\
\hline AF_budget & $0-5$ & 0.51 & 0.71 & $0-3$ & 0.54 & 0.75 & $0-3$ \\
\hline AF_exams & $0-5$ & 0.28 & 0.48 & $0-2$ & 0.41 & 0.65 & $0-3$ \\
\hline AF_parking & $0-5$ & 0.57 & 0.78 & $0-4$ & 0.54 & 0.83 & $0-4$ \\
\hline AF_cancer & $0-5$ & 0.38 & 0.61 & $0-3$ & 0.42 & 0.65 & $0-3$ \\
\hline AOT1 & $1-5$ & 4.20 & 0.86 & $1-5$ & 4.12 & 0.96 & $1-5$ \\
\hline AOT2 & $1-5$ & 4.75 & 0.45 & $3-5$ & 4.34 & 0.88 & $1-5$ \\
\hline AOT $^{a}$ & $1-5$ & 2.10 & 0.98 & $1-5$ & 3.13 & 1.19 & $1-5$ \\
\hline AOT4 & $1-5$ & 4.76 & 0.43 & $3-5$ & 4.43 & 0.74 & $1-5$ \\
\hline AOT5 $^{a}$ & $1-5$ & 1.19 & 0.40 & $1-3$ & 1.94 & 1.05 & $1-5$ \\
\hline AOT6 & $1-5$ & 4.14 & 0.92 & $1-5$ & 4.21 & 0.83 & $1-5$ \\
\hline AOT7 $^{\text {a }}$ & $1-5$ & 1.39 & 0.66 & $1-4$ & 2.49 & 1.24 & $1-5$ \\
\hline AOT8 $^{a}$ & $1-5$ & 1.83 & 0.91 & $1-5$ & 2.41 & 1.14 & $1-5$ \\
\hline АOT9 & $1-5$ & 3.86 & 1.09 & $1-5$ & 3.1 & 1.24 & $1-5$ \\
\hline
\end{tabular}




\begin{tabular}{lccccccc} 
AOT10 & $1-5$ & 4.73 & 0.46 & $3-5$ & 4.55 & 0.65 & $2-5$ \\
BSR1 & $1-5$ & 2.27 & 1.09 & $1-5$ & 2.92 & 1.24 & $1-5$ \\
BSR2 & $1-5$ & 1.98 & 1.03 & $1-5$ & 2.48 & 1.21 & $1-5$ \\
BSR3 & $1-5$ & 1.93 & 1.03 & $1-5$ & 2.6 & 1.17 & $1-5$ \\
BSR4 & $1-5$ & 2.05 & 1.02 & $1-5$ & 2.54 & 1.19 & $1-5$ \\
BSR5 & $1-5$ & 1.95 & 1.09 & $1-5$ & 2.73 & 1.22 & $1-5$ \\
BSR6 & $1-5$ & 1.82 & 1.11 & $1-5$ & 2.73 & 1.25 & $1-5$ \\
BSR7 & $1-5$ & 1.97 & 1.14 & $1-5$ & 2.65 & 1.29 & $1-5$ \\
BSR8 & $1-5$ & 2.49 & 1.16 & $1-5$ & 3 & 1.17 & $1-5$ \\
BSR9 & $1-5$ & 1.81 & 1.18 & $1-5$ & 2.32 & 1.33 & $1-5$ \\
BSR10 & $1-5$ & 1.99 & 1.11 & $1-5$ & 2.28 & 1.13 & $1-5$ \\
\hline
\end{tabular}

${ }^{a}$ Reverse-coded items (i.e., lower values reflect higher AOT). $M=$ Mean; $S D=$ Standard Deviation; AOT = Actively Open-Minded Thinking; BSR = Pseudo-Profound Bullshit Receptivity; AF = Attribute Framing; RC = Risky-Choice Framing

\section{Confirmatory Analyses}

Contrary to Hypothesis 3a, the hypothesized model did not fit acceptably (Table 4). As pre-registered, we modified the model based on the highest modifications index $(m i=18.66)$ and added a residual covariance between BSR6 ("We are in the midst of a self-aware blossoming of being that will align us with the nexus itself.") and BSR9 ("We are in the midst of a highfrequency blossoming of interconnectedness that will give us access to the quantum soup itself."). This modification can also be theoretically justified, as the wording of the two items is similar. The results of fitting the modified model can be found in Figure 2. ${ }^{1}$

\footnotetext{
${ }^{1}$ We had pre-registered that we would continue to modify the model until the BIC can no longer be improved, which resulted in 18 model modifications (Supplement 2, Table C1; Geiger et al., 2019). As this seemed infeasible, we deviated from our plan and preferred the more parsimonious model with one modification. This deviation did not change any of the conclusions about the hypotheses (Supplement 2, Table C1; Geiger et al., 2019).
} 


\section{Figure 2}

Modified Model Including Standardized Parameters: North America

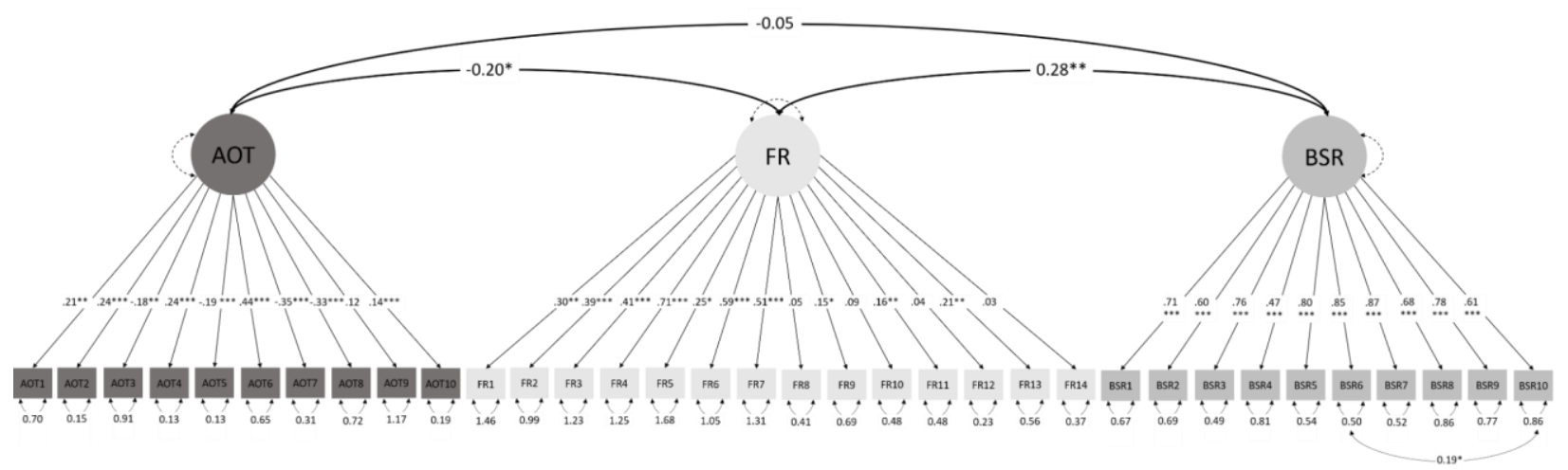

Note. $* p<.05, * * p<.01, * * * p<.001$

The modified model fit the data better than the hypothesized model, as shown by a significant likelihood-ratio test as well as a lower AIC and BIC for the modified model (Table 4). Despite no exact fit of the modified model, $\chi^{2}(523)=669.28, p<.001$ (scaling correction factor: 1.07), most robust fit indices now indicated acceptable, good, or excellent fit, $\mathrm{CFI}=0.89$, IFI $=$ 0.89, RMSEA $=.03,90 \% \mathrm{CI}[.03, .04]$, and SRMR $=.06$. Only the robust TLI/NNFI still indicated questionable fit, TLI/NNFI $=0.88$. The model with the residual covariance between BSR6 and BSR9 thus fit the data acceptably and was used to test Hypothesis 1a and 2a. 
ACTIVELY OPEN-MINDED THINKING, BULLSHIT RECEPTIVITY, AND FRAMING 18

\section{Table 4}

Fit and Comparison of the Hypothesized and Modified Model: North America

\begin{tabular}{|c|c|c|c|c|c|c|c|c|c|c|c|}
\hline Model & $\begin{array}{l}\chi^{2}(d f) \\
\text { robust }\end{array}$ & $\begin{array}{c}p \\
\text { robust }\end{array}$ & $\begin{array}{c}\text { RMSEA } \\
\text { robust }\end{array}$ & $\begin{array}{c}\text { CFI } \\
\text { Robust }\end{array}$ & $\begin{array}{c}\text { TLI/NNFI } \\
\text { robust }\end{array}$ & $\begin{array}{c}\text { IFI } \\
\text { scaled }\end{array}$ & $\begin{array}{l}\text { SRMR } \\
\text { Bentler }\end{array}$ & AIC & BIC & $\Delta \chi^{2}(\Delta d f)$ & $p$ \\
\hline $\begin{array}{l}\text { Hypothesized } \\
\text { model }\end{array}$ & $684.77(524)$ & $<.001$ & $\begin{array}{c}0.04 \\
\mathrm{CI}[0.03,0.04]\end{array}$ & 0.88 & 0.87 & 0.88 & 0.06 & 21,496 & 21,749 & & \\
\hline $\begin{array}{l}\text { Modified model } \\
\text { (BSR6 BSR9) }\end{array}$ & $669.28(523)$ & $<.001$ & $\begin{array}{c}0.03 \\
\text { CI[0.03, 0.04] }\end{array}$ & 0.89 & 0.88 & 0.89 & 0.06 & 21,480 & 21,737 & $8.43(1)$ & .004 \\
\hline
\end{tabular}

Note. AIC $=$ Akaike Information Criterion; BIC $=$ Bayesian Information Criterion; $\mathrm{CFI}=$ Comparative Fit Index; $\mathrm{CI}=90 \%$ Confidence Interval; $\mathrm{IFI}=$ Incremental Fit Index; SRMR = Standardized Root Mean Square Residual; RMSEA = Root Mean Square Error of Approximation; TLI/NNFI = Tucker-Lewis Index/Non-Normed Fit Index 
As predicted in Hypothesis 1a, AOT and susceptibility to framing were negatively correlated, $r=-.20,95 \%$ CI [-.37, -.02], SE $=.09, p=.029$. As predicted in Hypothesis 2a, BSR and susceptibility to framing were positively correlated, $r=.28,95 \% \mathrm{CI}[.12, .44], \mathrm{SE}=.08, p<$ .001. The associations are illustrated on Figure 3 (see Supplement 3 for correlations based on means, Geiger et al., 2019).

\section{Figure 3}

Associations Between Factor Scores of AOT, BSR, and Susceptibility to Framing: North America
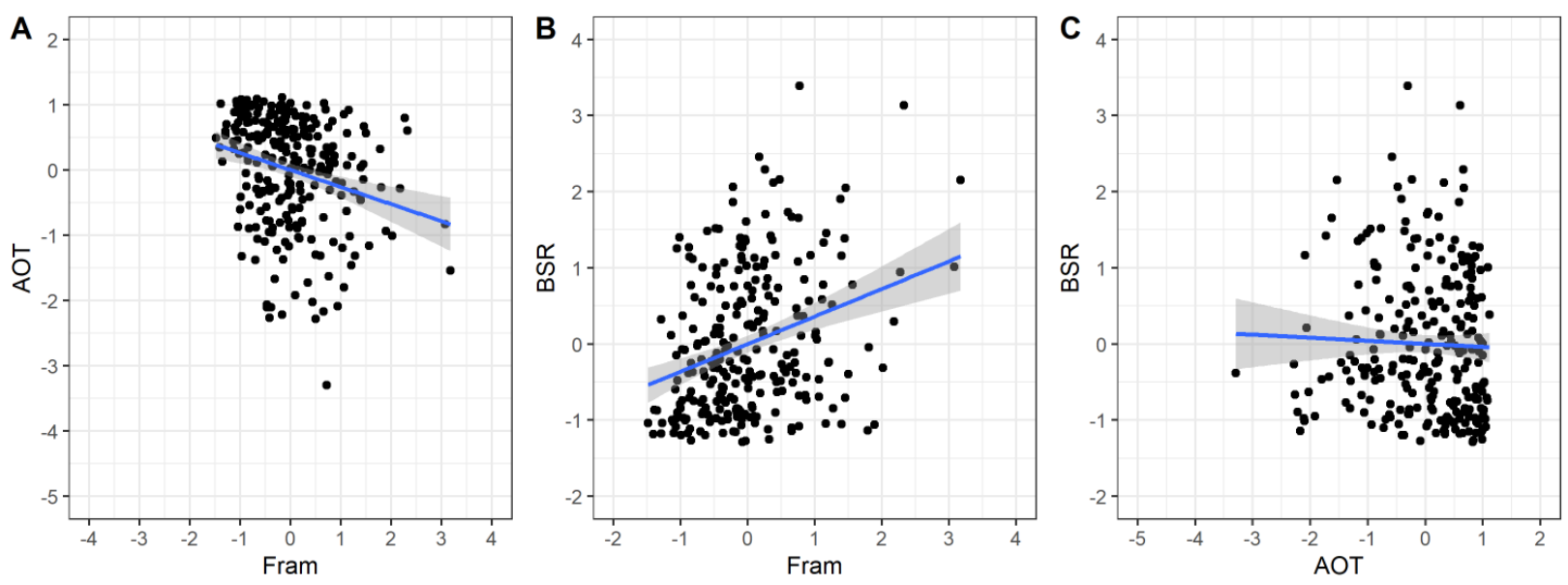

\section{Study 2: Bulgaria}

\section{Descriptive Statistics and Reliability}

Susceptibility to framing and BSR were low, while AOT was high (Table 3).

Susceptibility to framing and AOT displayed questionable reliability (McDonald's $\omega_{1}=.44$ and .52 respectively); however, the BSR scale was reliable (McDonald's $\left.\omega_{1}=.84\right)$. These results mirror those from North America. 


\section{Confirmatory Analyses}

The results of fitting the hypothesized model to the data are displayed in Figure 4. Supporting Hypothesis $3 b$, the model fit acceptably according to our pre-specified criteria. Even though the $\chi^{2}$-test indicated no exact fit, $\chi^{2}(524)=610.67, p=.005$ (scaling correction factor: 1.07), the robust fit indices suggested acceptable to excellent fit, $\mathrm{CFI}=0.89$, TLI/NNFI $=0.887$, $\mathrm{IFI}=0.90, \mathrm{RMSEA}=.03,90 \%$ CI $[.02, .04]$, and $\mathrm{SRMR}=.07$.

\section{Figure 4}

Hypothesized Model Including Standardized Parameters: Bulgaria

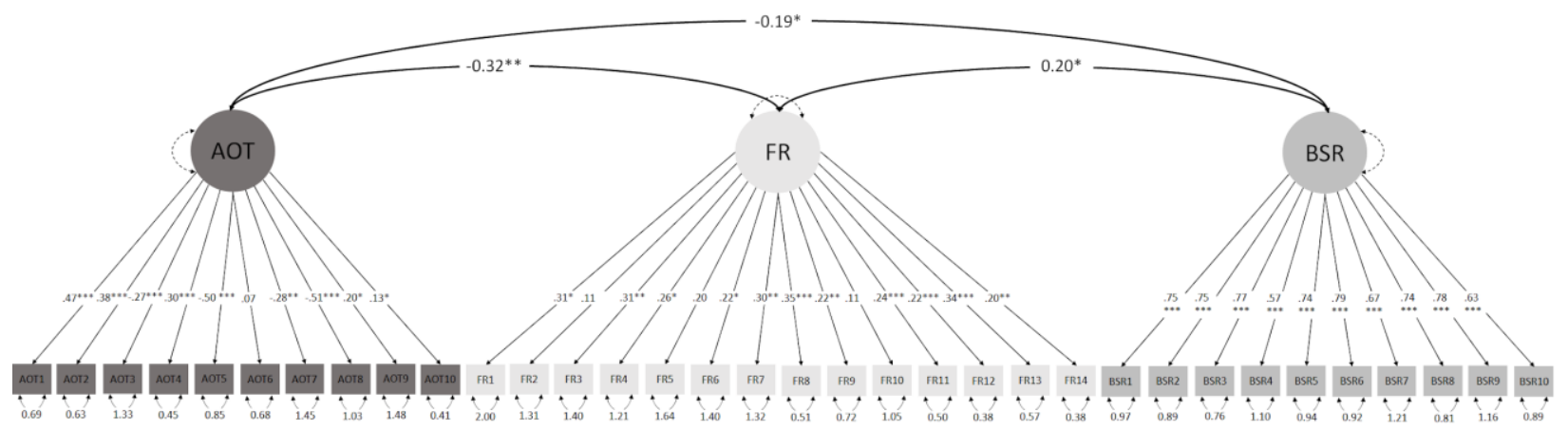

Note. $* p<.05, * * p<.01, * * * p<.001$.

Supporting Hypothesis 1b, AOT and susceptibility to framing were negatively correlated, $r=-.32,95 \% \mathrm{CI}[-.56,-.08], \mathrm{SE}=.12, p=.008$. As predicted by Hypothesis $2 \mathrm{~b}, \mathrm{BSR}$ and susceptibility to framing were positively correlated, $r=.20,95 \% \mathrm{CI}[.01, .38], \mathrm{SE}=.09, p=$ .036. The associations are illustrated in Figure 5.

\section{Figure 5}

Associations Between Factor Scores of AOT, BSR, and Susceptibility to Framing: Bulgaria 

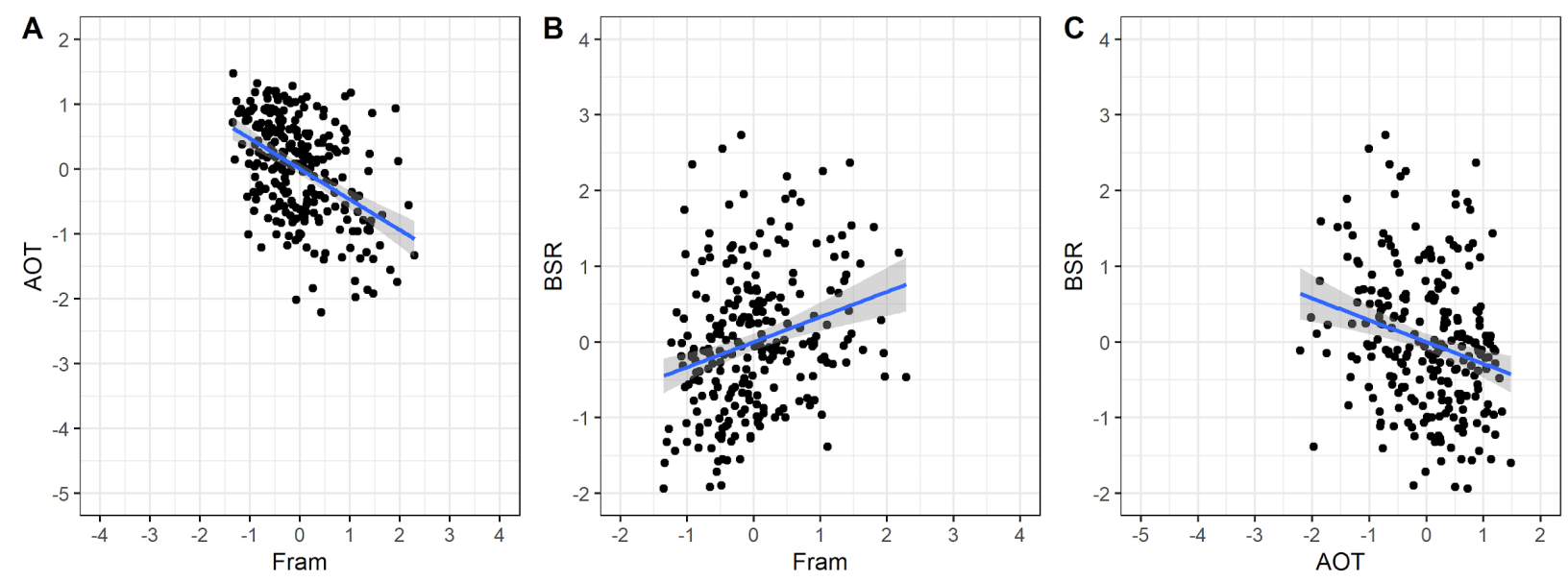

\section{Exploratory Measurement Invariance}

Exploratory multi-group CFA $(N=507)$ tested whether the hypothesized associations differed between sites. To achieve partial strong invariance, we needed to add a covariance between BSR6 and BSR9 $(m i=18.66)$, as we did earlier in the North American model, as well as free two factor loadings and 12 intercepts. Since at least two items per factor remained invariant (Cieciuch \& Davidov, 2015), results could thus be meaningfully compared between North America and Bulgaria.

To test differences between sites, we constrained all latent correlations to be equal between sites. This constrained model fit worse than the partial strong invariance model (Table 5), suggesting that the correlations differed between sites. Using the partial strong invariance model, a two-tailed test for independent correlations (R package $p s y c h$, Version 1.9.12.31; Revelle, 2020) revealed that the AOT-framing correlation was larger in Bulgaria $(r=-.41)$ than in North America $(r=-.24, z=2.23, p=.025)$. However, there was no evidence for different BSR-framing correlations between sites (North America: $r=.30$, Bulgaria: $r=.21, z=1.06, p=$ $.291)$. 
ACTIVELY OPEN-MINDED THINKING, BULLSHIT RECEPTIVITY, AND FRAMING 22

\section{Table 5}

Fit and Comparison for Measurement Invariance Testing

\begin{tabular}{|c|c|c|c|c|c|c|c|c|c|c|c|}
\hline Model & $\begin{array}{l}\chi^{2}(d f) \\
\text { robust }\end{array}$ & $\begin{array}{c}p \\
\text { robust }\end{array}$ & $\begin{array}{l}\text { RMSEA } \\
\text { robust }\end{array}$ & $\begin{array}{c}\mathrm{CFI} \\
\text { robust }\end{array}$ & $\begin{array}{l}\text { TLI/NNFI } \\
\text { robust }\end{array}$ & $\begin{array}{c}\text { IFI } \\
\text { scaled }\end{array}$ & $\begin{array}{l}\text { SRMR } \\
\text { Bentler }\end{array}$ & AIC & $\mathrm{BIC}$ & $\Delta \chi^{2}(\Delta d f)$ & $p$ \\
\hline Configural invariance & $\begin{array}{c}1,295.31 \\
(1,048)\end{array}$ & $<.001$ & $\begin{array}{c}.03 \\
\text { CI }[.03, .04]\end{array}$ & 0.885 & 0.88 & 0.889 & .06 & 45,586 & 46,468 & & \\
\hline $\begin{array}{l}\text { Partial configural } \\
\text { invariance } \\
\text { (BSR6 BSR9) }\end{array}$ & $\begin{array}{c}1,279.26 \\
(1,046)\end{array}$ & $<.001$ & $\begin{array}{c}.03 \\
\text { CI[.02, .04] }\end{array}$ & 0.89 & 0.88 & 0.90 & .06 & 45,571 & 47,474 & $10.79(2)$ & .005 \\
\hline Weak invariance & $\begin{array}{c}1,353.22 \\
(1,077)\end{array}$ & $<.001$ & $\begin{array}{c}.03 \\
\text { CI }[.03, .04]\end{array}$ & 0.87 & 0.87 & 0.87 & .07 & 45,587 & 46,352 & $76.31(31)$ & $<.001$ \\
\hline $\begin{array}{l}\text { Partial weak invariance } \\
\text { (Fram = } \\
\text { AOT }=\sim \text { AOTd disease, }\end{array}$ & $\begin{array}{c}1,330.10 \\
(1,075)\end{array}$ & $<.001$ & $\begin{array}{c}.03 \\
\text { CI[.03, .04] }\end{array}$ & 0.88 & 0.88 & 0.88 & .07 & 45,568 & 46,341 & $50.83(29)$ & .007 \\
\hline Strong invariance & $\begin{array}{c}1,449.62 \\
(1,106)\end{array}$ & $<.001$ & $\begin{array}{c}.04 \\
\text { CI[.03, } .04]\end{array}$ & 0.84 & 0.84 & 0.84 & .07 & 45,621 & 46,341 & $151.26(31)$ & $<.001$ \\
\hline $\begin{array}{l}\text { Partial strong invariance } \\
(12 \text { intercepts freed })^{2}\end{array}$ & $\begin{array}{c}1,368.59 \\
(1,094)\end{array}$ & $<.001$ & $\begin{array}{c}.03 \\
\text { CI }[.03, .04]\end{array}$ & 0.87 & 0.87 & 0.87 & .07 & 45,565 & 46,259 & $42.29(19)$ & .002 \\
\hline $\begin{array}{l}\text { Equal variances and } \\
\text { covariances }\end{array}$ & $\begin{array}{c}1,384.29 \\
(1,100)\end{array}$ & $<.001$ & $\begin{array}{c}.03 \\
\text { CI }[.03, .04]\end{array}$ & 0.87 & 0.87 & 0.87 & .07 & 45,571 & 46,239 & $14.98(6)$ & .020 \\
\hline
\end{tabular}

Note. AIC = Akaike Information Criterion; BIC = Bayesian Information Criterion; $\mathrm{CFI}=$ Comparative Fit Index; CI = 90\% Confidence Interval; IFI = Incremental Fit Index; SRMR = Standardized Root Mean Square Residual; RMSEA = Root Mean Square Error of Approximation; TLI/NNFI = Tucker-Lewis Index/Non-Normed Fit Index

${ }^{1}$ Compared to the partial configural invariance model.

${ }^{2}$ Compared to partial weak invariance model. 


\section{Discussion}

Although the framing effect is a robust phenomenon, different conflicting explanations of it exist. In particular, the dual-process account conceives of the framing effect as a deviation from rational thought. However, this view has recently been contested (e.g., Mandel, 2014). To advance the debate, we tested two predictions derived from the dual-process framework regarding the association between susceptibility to thinking and two qualities of rational thought, actively-open minded thinking (AOT) and pseudo-profound bullshit receptivity (BSR). Using a within-subjects administration of framing tasks, we found a negative association between AOT and susceptibility to framing as well as a positive association between BSR and susceptibility to framing among North Americans and Bulgarians. When provided with a cue, individuals who are more willing and able to think analytically are less susceptible to framing, among other thinking biases (Pennycook, Fugelsang, et al., 2015b). However, the small to moderate associations point to additional factors other than thinking dispositions.

One such factor is the alternative interpretation of framing tasks (Kühberger \& Tanner, 2010; Mandel, 2014; Sher \& McKenzie, 2006), which is, however, unlikely in this study. If individuals interpreted the two versions of a framing task as different rather than equivalent, they would shift their preferences depending on the task version. Such instances of justified reconsideration would be misclassified as susceptibility to framing, leading to an underestimated association between thinking qualities and the use of a superior decision strategy given one's interpretation. However, the small mean differences between the two versions of the framing tasks (Table 3) suggest that most participants interpreted the two versions as equivalent, and importantly, participants who were more willing and able to think analytically had an advantage 
in following the normative principle. Hence, the modest correlations cannot be explained based on different interpretations of the framing tasks.

The more important question is whether associations of this magnitude favor the dualprocess account. Basing our expected effect size on previous research (Pennycook, Cheyne, et al., 2015; Rachev et al., 2021; Toplak et al., 2011; Turpin et al., 2019), we implicitly set the smallest effect size of interest (Lakens, 2017) to a value that might seem too low to critics of the dual-process account of framing (Mandel \& Kapler, 2018). Our results show that neither overclaiming nor ignoring the role of thinking dispositions in resisting framing is warranted. Therefore, any theory aiming to thoroughly account for individual differences in susceptibility to framing should incorporate the small but non-negligible associations with thinking dispositions. The dual-process view might also need updating to predict not only the direction but also the magnitude of the associations.

\section{Cross-National Generalizability}

Testing the hypotheses among North Americans and Bulgarians broadened the scope of research on framing and thinking dispositions by going beyond Western samples dominating previous research (Henrich et al., 2010). In both sites, actively open-minded thinking was negatively and bullshit receptivity was positively associated with susceptibility to framing; however, the former association was stronger in Bulgaria than North America. This means that our results generalize between sites in terms of direction and, partially, in terms of magnitude. Apparently, similar mechanisms played a role in responding to the tasks in both sites, despite the many potential differences between the two samples pertinent to decision making and thinking dispositions (Rachev \& Petkova, 2019). Moreover, adapting the measures to a novel setting can support future research among a so far understudied population. 


\section{Considerations Related to Measurement}

Confirmatory factor analysis (CFA) has rarely been used in studies on framing. Compared to multiple regression, CFA corrects for measurement unreliability and thus provides more reliable evidence (Westfall \& Yarkoni, 2016). We believe that a CFA approach is especially warranted in framing research, as the Resistance to Framing scale usually shows low reliability, with Cronbach's a ranging from .48 (Del Missier et al., 2012) to .62 (Bruine de Bruin et al., 2007; see also Stanovich et al., 2016), and McDonald's $\omega_{1}=.55$ (North America) and .44 (Bulgaria) in this study. The low internal consistency of the scale might also be one reason why the reported correlations with other measures of rational thought and action have been relatively low (Bruine de Bruin et al., 2007; Stanovich et al., 2016). Importantly, some have used the finding that resistance to framing does not reliably predict everyday decision outcomes (Bruine de Bruin et al., 2007) to argue that resistance to framing is not a valid measure of rational behavior (Aczel et al., 2018). Our approach suggests that the low correlations might, at least in part, be due to the low reliability of the scale which should be explicitly corrected for by researchers.

\section{Limitations and Future Directions}

Our study has several limitations. One limitation concerns the questionable fit of our original CFA model in North America, contrary to our Hypotheses 3a. Accordingly, we modified the hypothesized model by adding a residual covariance between two BSR items with very similar wording. Model modifications, however, did not influence the hypothesized associations between variables (Figure 2).

We collected data from university students in both sites to construct samples that are comparable in terms of potentially important demographics. However, highly educated 
individuals differ from other individuals of their nations in many important respects, so the present findings might not generalize to the whole populations (Henrich et al., 2010).

More generally, our correlational evidence, though broadly consistent with the dualprocess account, does not speak directly to the potential underlying mechanisms. Future research can test for the nature of these mechanisms using paradigms from recent advances in dualprocess theorizing (De Neys \& Pennycook, 2019), such as requesting a response once under time pressure or cognitive load, and a second time with no such additional demands. This paradigm can provide evidence if effortful Type 2 processing is indeed crucial for resolving the conflict between the frame and the invariance principle, as posited by the traditional defaultinterventionist view (Evans \& Stanovich, 2013; Kahneman, 2003). In contrast, the more recent view proposes that the conflict arises between competing Type 1 intuitions, some consistent with while others contradicting normative considerations (De Neys, 2018; De Neys \& Pennycook, 2019). Pitting the two views against each other, one can find out if individuals who are more willing and able to think analytically resist framing better by virtue of engaging in more effortful thinking or by displaying stronger normative intuitions.

\section{Conclusion}

We found small to medium associations between two qualities of thinking — activelyopen minded thinking and pseudo-profound bullshit receptivity—and susceptibility to framing. Our findings broadly support the dual-process account of the framing effect and challenge accounts contesting the irrationality behind the framing effect. Our findings further suggest that the associations are generalizable beyond Western samples. We thus open the door for future research across borders and populations, that would address the mechanisms underlying these associations and refine theory related to both dual processes and framing. 


\section{Open Science}

Open Data: We confirm that there is sufficient information for an independent researcher to reproduce all of the reported results, including codebooks (Geiger et al., 2019).

Open Materials: We confirm that there is sufficient information for an independent researcher to reproduce all of the reported methodology (Geiger et al., 2019).

Preregistration of Studies and Analysis Plans: This study was preregistered with an analysis plan (Geiger et al., 2020).

\section{Author Contribution Statement}

Nikolay R. Rachev: Conceptualization, Methodology, Investigation, Writing - Original Draft, Writing - Review \& Editing, Supervision, Project Administration, Funding Acquisition

Sandra J. Geiger: Conceptualization, Methodology, Validation, Formal analysis, Investigation, Data Curation, Writing - Original draft, Writing - Review \& Editing, Visualization, Project administration

Jáchym Vintr: Conceptualization, Methodology, Formal analysis, Investigation, Validation, Writing - Review \& Editing

Desislava Kirilova: Conceptualization, Methodology, Investigation, Writing - Review and Editing

Anna Nabutovsky: Conceptualization, Methodology, Investigation, Project Administration, Resources, Writing - Review and Editing

Joakim Nelsson: Conceptualization, Methodology, Investigation, Data Curation, Writing - Review and Editing 


\section{Funding}

This research was partially supported by grants from the Faculty of Philosophy at Sofia University St. Kliment Ohridski and the University of Toronto.

\section{Acknowledgments}

This research was made possible thanks to the Junior Researcher Programme (JRP, http://jrp.pscholars.org/). We are grateful to everyone from the JRP team for their effort and support. We also thank Gordon Pennycook, Jonathan Baron, Wändi Bruine de Bruin, Andrew Parker, Baruch Fischhoff, Fabio Del Missier, and Irwin Levin for their helpful comments on the materials used in this study; David Mandel for sharing his co-authored dataset for the purpose of the power analysis; William Cunningham and the Social Cognition Lab at the University of Toronto for their resources; Sacha Epskamp, for his feedback on CFA; Student Councils and faculty at various Bulgarian universities, for their assistance in data collection; Laura Mtewele

for her contribution in the early stages of the project; Vanessa Bühler, for her contribution to the Stage 1 manuscript; and Julia Kamburidis, Ekaterina Peycheva, and Evelina Marinova for their work on the Bulgarian translations of the materials. 


\section{References}

Aczel, B., Szollosi, A., \& Bago, B. (2018). The effect of transparency on framing effects in within-subject designs. Journal of Behavioral Decision Making, 31(1), 25-39. https://doi.org/10.1002/bdm.2036

Baron, J. (1991). Beliefs about thinking. In J. F. Voss, D. N. Perkins, \& J. W. Segal (Eds.), Informal reasoning and education (pp. 169-186). Erlbaum.

Baron, J. (2008). Thinking and deciding (4th ed.). Cambridge University Press.

Baron, J. (2019). Actively open-minded thinking in politics. Cognition, 188, 8-18. https://doi.org/10.1016/j.cognition.2018.10.004

Baron, J., \& High II, D. (2019, November). People who endorse actively open-minded thinking (AOT) are sensitive to cues indicating AOT of sources [Poster Presentation]. Society for Judgment and Decision-Making Annual Meeting, Montréal, Canada. http://www.sjdm.org/presentations/2019-Poster-Baron-Jonathan-endorse-AOT-cues.pdf

Baron, J., Scott, S., Fincher, K., \& Metz, S. E. (2015). Why does the Cognitive Reflection Test (sometimes) predict utilitarian moral judgment (and other things)? Journal of Applied Research in Memory and Cognition, 4(3), 265-284. https://doi.org/10.1016/j.jarmac.2014.09.003

Bruine de Bruin, W., Parker, A. M., \& Fischhoff, B. (2007). Individual differences in adult decision-making competence. Journal of Personality and Social Psychology, 92(5), 938956. https://doi.org/10.1037/0022-3514.92.5.938

Cieciuch, J., \& Davidov, E. (2015). Establishing measurement invariance across online and offline samples: A tutorial with the software packages Amos and Mplus. Studia Psychologica: Theoria et Praxis, 2(15), 83-99. https://doi.org/10.21697/sp.2015.14.2.06 
Del Missier, F., Mäntylä, T., \& Bruine de Bruin, W. (2012). Decision-making competence, executive functioning, and general cognitive abilities. Journal of Behavioral Decision Making, 25(4), 331-351. https://doi.org/10.1002/bdm.731

De Neys, W. (2018). Bias, conflict, and fast logic: Towards a hybrid dual process future? In W. De Neys (Ed.), Dual process theory 2.0 (pp. 47-65). Routledge.

De Neys, W., \& Pennycook, G. (2019). Logic, fast and slow: Advances in dual-process theorizing. Current Directions in Psychological Science, 28(5), 503-509. https://doi.org/10.1177/0963721419855658

Evans, J. St. B. T., \& Stanovich, K. E. (2013). Dual-process theories of higher cognition: Advancing the debate. Perspectives on Psychological Science, 8(3), 223-241. https://doi.org/10.1177/1745691612460685

Fischer, R., \& Karl, J. A. (2019). A primer to (cross-cultural) multi-group invariance testing possibilities in R. Frontiers in Psychology, 10, Article e1507. https://doi.org/10.3389/fpsyg.2019.01507

Geiger, S. J., Rachev, N. R., Kirilova, D. K., Nelsson, J., Buehler, V., Vintr, J., \& Nabutovsky, A. (2019). Actively open-minded thinking, bullshit receptivity, and susceptibility to framing: Evaluating the dual-process account in North America and Bulgaria. (OSF Repository) https://doi.org/10.17605/OSF.IO/HX8QT

Geiger, S. J., Rachev, N. R., Kirilova, D. K., Nelsson, J., Buehler, V., Vintr, J., \& Nabutovsky, A. (2020, September 24). Actively open-minded thinking, bullshit receptivity, and susceptibility to framing: Evaluating the dual-process account in North America and Bulgaria. Preregistration available at osf.io/y6vsg 
Greiff, S., \& Allen, M. S. (2018). EJPA introduces Registered Reports as new submission format [Editorial]. European Journal of Psychological Assessment, 34(4), 217-219. https://doi.org/10.1027/1015-5759/a000492

Haran, U., Ritov, I., \& Mellers, B. A. (2013). The role of actively open-minded thinking in information acquisition, accuracy, and calibration. Judgment and Decision Making, 8(3), $188-201$.

Henrich, J., Heine, S. J., \& Norenzayan, A. (2010). The weirdest people in the world? Behavioral and Brain Sciences, 33(2-3), 61-83. https://doi.org/10.1017/S0140525X0999152X

Jorgensen, T. D., Pornprasertmanit, S., Schoemann, A. M., Rosseel, Y., Miller, P., Quick, C., Garnier-Villarreal, M., Selig, J., Boulton, A., Preacher, K., Coffman, D., Rhemtulla, M., Robitzsch, A., Enders, C., Arslan, R., Clinton, B., Panko, P., Merkle, E., Chesnut, S., ... Mansolf, M. (2019). semTools: Useful tools for Structural Equation Modeling (Version 0.5-2) [Computer software]. https://CRAN.R-project.org/package=semTools

Kahneman, D. (2003). A perspective on judgment and choice: Mapping bounded rationality. American Psychologist, 58(9), 697-720. https://doi.org/10.1037/0003-066X.58.9.697

Koo, M., \& Skinner, H. (2005). Challenges of internet recruitment: A case study with disappointing results. Journal of Medical Internet Research, 7(1), Article e6. https://doi.org/10.2196/jmir.7.1.e6

Koran, J. \& Jaffari, F. (2020). Deletion statistic accuracy in confirmatory factor models. Methodological Innovations, 13(2), 1-10. https://doi.org/10.1177/2059799120918349

Korkmaz, S., Goksuluk, D., \& Zararsiz, G. (2014). MVN: An R package for assessing multivariate normality. The R Journal, 6(2), 151-162. 
Kühberger, A. \& Tanner, C. (2010). Risky choice framing: Task versions and a comparison of prospect theory and fuzzy-trace theory. Journal of Behavioral Decision Making, 23(3), 314-329. https://doi.org/10.1002/bdm.656

Lakens, D. (2017, May 11). How a power analysis implicitly reveals the smallest effect size you care about. The 20\% Statistician. http://daniellakens.blogspot.com/2017/05/how-poweranalysis-implicitly-reveals.html

LeBoeuf, R. A. \& Shafir, E. (2003). Deep thoughts and shallow frames: On the susceptibility to framing effects. Journal of Behavioral Decision Making, 16(2), 77-92. https://doi.org/10.1002/bdm.433

Levin, I. P., Schneider, S. L., \& Gaeth, G. J. (1998). All frames are not created equal: A typology and critical analysis of framing effects. Organizational Behavior and Human Decision Processes, 76(2), 149-188. https://doi.org/10.1006/obhd.1998.2804

MacCallum, R. C., Browne, M. W., \& Sugawara, H. M. (1996). Power analysis and determination of sample size for covariance structure modeling. Psychological Methods, 1(2), 130-149. https://doi.org/10.1037/1082-989X.1.2.130

Mandel, D. R. (2014). Do framing effects reveal irrational choice? Journal of Experimental Psychology: General, 143(3), 1185-1198. https://doi.org/10.1037/a0034207

Mandel, D. R., \& Kapler, I. V. (2018). Cognitive style and frame susceptibility in decisionmaking. Frontiers in Psychology, 9, Article e1461. https://doi.org/10.3389/fpsyg.2018.01461

Pastore, M. \& Altoe' G. (2018). influence.SEM: Case influence in structural equation models (Version 2.2) [Computer software]. https://cran.rproject.org/web/packages/influence.SEM/index.html 
Pennycook, G., Cheyne, J. A., Barr, N., Koehler, D. J., \& Fugelsang, J. A. (2015). On the reception and detection of pseudo-profound bullshit. Judgment and Decision Making, $10(6), 549-563$.

Pennycook, G., Fugelsang, J. A., \& Koehler, D. J. (2015a). What makes us think? A three-stage dual-process model of analytic engagement. Cognitive Psychology, 80, 34-72. https://doi.org/10.1016/j.cogpsych.2015.05.001

Pennycook, G., Fugelsang, J. A., \& Koehler, D. J. (2015b). Everyday consequences of analytic thinking. Current Directions in Psychological Science, 24(6), 425-432. https://doi.org/10.1177/0963721415604610

Rachev, N., Pobornikova, G., Marinova, E., Beshkov, K., Benovska, A.-K., Tenev, D., Shomeva, M., Genev, E., \& Peycheva, E. (2021). Bulgarian data for pseudo-profound bullshit receptivity and resistance to framing [Data set]. Harvard Dataverse. https://doi.org/10.7910/DVN/RBB4KI

Rachev, N. R., \& Petkova, M. (2019). How prone are Bulgarians to heuristics and biases? Implications for studying rationality across cultures. Journal of Cognition and Culture, 19(3-4), 322-342. https://doi.org/10.1163/15685373-12340062

Revelle, W. (2020). psych: Procedures for psychological, psychometric, and personality research (Version 1.9.12.31) [Computer software]. https://CRAN.Rproject.org/package=psych

Rosseel, Y. (2012). lavaan: An R package for Structural Equation Modeling. Journal of Statistical Software, 48(1), 1-36. https://doi.org/10.18637/jss.v048.i02

Sher, S., \& McKenzie, C. R. M. (2006). Information leakage from logically equivalent frames. Cognition, 101(3), 467-494. https://doi.org/10.1016/j.cognition.2005.11.001 
Stanovich, K. E., West, R. F., \& Toplak, M. E. (2016). The rationality quotient: Toward a test of rational thinking. MIT Press.

Toplak, M. E., West, R. F., \& Stanovich, K. E. (2011). The Cognitive Reflection Test as a predictor of performance on heuristics-and-biases tasks. Memory \& Cognition, 39(7), 1275-1289. https://doi.org/10.3758/s13421-011-0104-1

Turpin, M. H., Walker, A. C., Kara-Yakoubian, M., Gabert, N. N., Fugelsang, J. A., \& Stolz, J. A. (2019). Bullshit makes the art grow profounder. Judgment and Decision Making, 14(6), 658-670.

Tversky, A., \& Kahneman, D. (1981). The framing of decisions and the psychology of choice. Science, 211(4481), 453-458. https://doi.org/10.1126/science.7455683

Tversky, A. \& Kahneman, D. (1986). Rational choice and the framing of decisions. Journal of Business, 59(4), S251-S278. https://doi.org/10.1086/296365

Wang, Y. A. \& Rhemtulla, M. (2020). Power analysis for parameter estimation in structural equation modeling: A discussion and tutorial. PsyArXiv. https://doi.org/10.31234/osf.io/pj67b

West, R. F., Toplak, M. E., \& Stanovich, K. E. (2008). Heuristics and biases as measures of critical thinking: Associations with cognitive ability and thinking dispositions. Journal of Educational Psychology, 100(4), 930-941. https://doi.org/10.1037/a0012842

Westfall, J. \& Yarkoni, T. (2016). Statistically controlling for confounding constructs is harder than you think. PLOS ONE, 11(3), Article e0152719. https://doi.org/10.1371/journal.pone.0152719 